\title{
Interpreting pathologies in extant and extinct archosaurs using micro-CT
}

Jennifer Anné, Russell J Garwood, Tristan Lowe, Philip J Withers, Philip L Manning

Palaeopathology offers unique insight to the healing strategies of extinct organisms, permitting questions concerning bone physiology to be answered in greater depth. Unfortunately, most palaeopathological studies are confined to external morphological interpretations due to the destructive nature of traditional methods of study. This limits the degree of reliable diagnosis and interpretation possible. X-ray MicroTomography (micro-CT, XMT) provides a non-destructive means of analysing the internal threedimensional structure of pathologies in both extant and extinct individuals, at higher resolutions than possible with medical scanners. In this study we present external and internal descriptions of pathologies in extant and extinct archosaurs using XMT. This work demonstrates that the combination of external/internal diagnosis that X-ray microtomography facilitates is crucial when differentiating between pathological conditions. Furthermore, we show that the use of comparative species, both through direct analysis and from the literature, provides key information for diagnosing between vertebrate groups in the typical pathological conditions and physiological processes. MicroCT imaging, combined with comparative observations of extant species, provides more detailed and reliable interpretation of palaeopathologies. Micro-CT is an increasingly accessible tool, which will provide key insights for correctly interpreting vertebrate pathologies in the future. 


\section{Interpreting pathologies in extant and extinct archosaurs using micro-CT}

2

3

4

5

6

7

8

9

10

11

12
Jennifer Anné ${ }^{*}$, Russell J. Garwood ${ }^{1}$, Tristan Lowe ${ }^{2}$, Philip J. Withers ${ }^{2}$ and Phillip L. Manning ${ }^{1}$

${ }^{1}$ School of Earth, Atmospheric and Environmental Sciences, University of Manchester, Manchester M13 9PL, UK

${ }^{2}$ Manchester X-ray Imaging Facility, School of Materials, University of Manchester, Manchester M13 9PL, UK

*jennifer.anne@manchester.ac.uk 


\begin{abstract}
Palaeopathology offers unique insight to the healing strategies of extinct organisms, permitting questions concerning bone physiology to be answered in greater depth. Unfortunately, most palaeopathological studies are confined to external morphological interpretations due to the destructive nature of traditional methods of study. This limits the degree of reliable diagnosis and interpretation possible. X-ray MicroTomography (micro-CT, XMT) provides a non-destructive means of analysing the internal three-dimensional structure of pathologies in both extant and extinct individuals, at higher resolutions than possible with medical scanners. In this study we present external and internal descriptions of pathologies in extant and extinct archosaurs using XMT. This work demonstrates that the combination of external/internal diagnosis that X-ray microtomography facilitates is crucial when differentiating between pathological conditions. Furthermore, we show that the use of comparative species, both through direct analysis and from the literature, provides key information for diagnosing between vertebrate groups in the typical pathological conditions and physiological processes. Micro-CT imaging, combined with comparative observations of extant species, provides more detailed and reliable interpretation of palaeopathologies. Micro-CT is an increasingly accessible tool, which will provide key insights for correctly interpreting vertebrate pathologies in the future.
\end{abstract}

\title{
Introduction
}

Palaeopathology is the study of ancient diseases and trauma, and is usually limited in vertebrates to lesions that affect the skeleton, as soft tissues are generally lost over time (Rothschild \& Martin, 2006; Rühli et al., 2007; Straight, 2009; Waldron, 2009; Rothschild \& Depalma, 2013). The identification and classification of palaeopathologies can be difficult due to complex internal morphology and the loss of detail during fossilisation due to taphonomic overprint. Despite these problems, most palaeopathological studies rely on external gross morphological descriptions rather than examining internal features. Although some palaeopathologies can be identified by external examination (e.x. fracture callus) a lack of internal morphological information may lead to misidentification and over interpretation. Internal structure can be identified using thin section analysis, but this method is destructive and therefore cannot be applied to specimens that are rare or fragile. Additionally, the two-dimensional nature of this technique does not capture the entire complexity of pathological tissue unless serial sections are made. The application of medical scanners to such material has allowed for non-destructive three-dimensional investigation of internal histologic superstructures, though the resolution may be low (Straight, 2009; Particelli et al., 2012; Sutton et al., 2014), and medical X-ray sources struggle to penetrate dense fossils.

Since the 1990's, XMT has revolutionised the study of fine and complex bone structures in medical (Englke et al., 1999; Particelli et al., 2012), forensic (Thali et al., 2003) and palaeontological studies (Straight, 2009; Sutton et al., 2014;Bishop et al., 2015; Foth et al., 2015). Such scanners can attain sub-micron resolution (depending on sample size) compared to the tenths of a millimetre in conventional medical scans (Englke et al., 1999; Sutton et al., 2014). XMT is usually applied to smaller samples, as the size of the area of interest dictates spatial resolution. However, by compromising the resolution of the scan (to tens of microns versus submicron), this technique can be applied to larger scan areas while maintaining higher resolution scans than is possible with medical scanners (which also struggle with large specimens due to their medium energy (20-150kV)). For example, the Nikon custom bay microtomography system in the Manchester X-ray Imaging Facility (MXIF) houses a high energy source (225-320 keV) 
that, coupled with a $2000 \times 2000$ pixel detector, allows decimetre-scale specimens of fossil bone to be scanned at sub-100 $\mu \mathrm{m}$ resolution. This level of detail allows us to distinguish key internal morphological features required for an accurate diagnosis of palaeopathologies. Here we present XMT data from two extant and three extinct archosaurs exhibiting a variety of pathologies, further demonstrating that XMT is a powerful tool for the field of palaeopathology.

\section{Materials \& Methods}

Specimens consisted of extant and extinct archosaur material with various pathological conditions that were identified based on external observations (Table 1).

Extant taxa were included to improve palaeopathological diagnosis as medical terminology, physiology of skeletal elements, and likelihood of certain diseases can differ, even between human and mammalian companion animals (Huchzermyer and Cooper, 2000; Rothschild \& Panza, 2005; Mader, 2006; Rothschild \& Martin, 2006; Rothschild, 2010; Kranenburg et al., 2013; Foth et al., 2015).

XMT scanning was conducted at the Manchester X-Ray Imaging Facility (MXIF) using the Nikon Metris Custom Bay, a system which can accommodate large specimens (maximum field of view of $410 \mathrm{~mm}$ ) and provide spatial resolutions between 100 and $\sim 3.5 \mu \mathrm{m}$. The system has a $225 \mathrm{kV}$ static multi-metal anode target, which was set to tungsten in order to achieve the maximum energy, to improve X-ray penetration of the scanned material (fossil and extant bone). The source voltage was set to $225 \mathrm{kV}$ and auto conditioned for 30 minutes prior to scanning to decrease the likelihood of the source cutting out while scanning. Specimens were mounted on a manipulation stage using a variety of plates and clamps depending on their size, weight, and geometry. Previous scans of this type of material have demonstrated that $15-20 \%$ transmission through the specimen relative to the flat field provide excellent scans. To achieve this aim, the source voltage and current were modified coupled with changing thicknesses of $\mathrm{Cu}$ or $\mathrm{Al}$ filters to minimise beam hardening but achieve an optimal spectral width and intensity. Exposure was selected to minimise scan times while collecting clean data (between 0.5 and 1.0 seconds exposure, sample dependent), and for all scans counts on the detector panel outside the sample were kept below 65,000 counts for the selected gain, which was set to minimum to reduce noise. For each sample scanning parameters were selected to fit these requirements while using the lowest voltage possible to maximise the attenuation from photoelectric absorption and thus maximise contrast from compositional differences in the sample (Sutton et al., 2014). 3,142 projections were collected; a number based on the optimise option for the CT Pro acquisition software.

Volumes were reconstructed using the Nikon CT Pro software. Processed scans were converted to TIFF stacks using the HMtool in MATLAB ${ }^{\circledR}$, which is an in-house script used by the MXIF. TIFFs or VGI/VOL files (the former for Volume Graphics' VGStudio MAX) were opened using Fiji (Schindelin et al., 2012) for initial analysis of slice stacks. TIFFs were then opened in Avizo ${ }^{\circledR}$ to construct orthoslices, while VGI files were opened in Drishti for volume rendering (Limaye, 2006).

\section{Results and Discussion}


NHM S/1869.2.16.1: Extensive bone growth persists through the interior of the S. serpentarius phalanx. In many locations, this makes distinguishing normal cancellous struts from pathological growth difficult (Figure 1). Despite the degree of pathological intrusion, both articular surfaces maintain shape and texture. A large, circular lesion is located on the plantar surface, with signs of necrosis internally. The concentric ring appearance within the necrotic area matches the description for a fibricess; a localised inflammatory process caused by the incomplete elimination of pathogens in archosaurs (Harmon, 1998; Huchzermyer \& Cooper, 2000). The most likely cause is osteitis (inflammation of the bone by infection) or osteomyelitis (inflammation of bone marrow by infection; Ritchie, Harrison \& Harrison, 1994; Berners, 2002). This diagnosis is based on the lesion on the plantar surface of the bone (Figure 1E), and internal necrosis (Figure 1B-D). In avians, bacterial osteomyelitis is identified based on severe necrosis, with minimal periosteal reaction (Ritchie, Harrison \& Harrison, 1994). However, periosteal change can occur in chronic infections, and in fungal osteomyelitis, the periosteal reaction is pronounced (Ritchie, Harrison \& Harrison, 1994). Additionally, there seems to be discrepancies between veterinary diagnoses as some characterise osteomyelitis as having a pronounced periosteal reaction (Doneley, 2011).

Due to the extent of the new growth, it is impossible to distinguish if the infection was a result of a fracture, or another complication such as ulcerative pododermatitis (bumblefoot; Herman, Locke \& Clark, 1962; Keymer. 1972; Remple and Al-AShbal. 1993; Ritchie, Harrison \& Harrison, 1994; Gentz, 1996; Huchzermyer and Cooper, 2000; Berners, 2002; Wyss et al., 2015), which can cause osteomyelitis in later stages. Pododermatitis is caused by a number of bacteria and is more common in captive individuals with poor perching surfaces. However, it has been documented in wild individuals, usually as a result of a puncture (Herman, Locke \& Clark, 1962; Keymer. 1972; Remple and Al-Ashbal. 1993; Gentz, 1996; Berners, 2002; Wyss et al., 2015). Additionally, most studies on pododermatisis concerning birds of prey focus on species that hunt 'on the wing'. Secretary birds spend most of their time foraging on hard ground, using their feet to stamp their prey. Thus pododermatisis is a reasonable hypothesis for the cause of osteomyelitis.

Excluded conditions include gout, osteopetrosis and neoplasia. Gout is a common metabolic disease in archosaurs caused by concentration of urate crystals (Berners; 2002; Mader 2006). Although common in wild birds (Morishita, Aye and Brooks, 1997), especially within the pedal phalanges, gout affects the joint surfaces, which in this specimen are unaffected (Mader, 2006). Osteopetrosis causes thickening of the bone through prolific bone deposition, resulting in the loss of the medullary cavity (Ritchie, Harrison \& Harrison, 1994; Doneley, 2011); however this is has only been noted in the femur, ulna, radius, pectoral girdle and vertebrae (in captive birds). Neoplasia is the most likely of the alternative, as it resembles osteomyelitis; however neoplasia is rare in wild individuals (Ritchie, Harrison \& Harrison, 1994).

BHI 6241: The outer appearance of the $S$. camelus cervical matches descriptions for early stages of Diffuse Idiopathic Skeletal Hyperostosis (DISH). DISH is described (externally) as fused vertebrae with a 'melted candle wax' appearance, where fusion may be asymmetrical and the articulated surfaces appear unaffected (Figure 2A; Rothschild \& Martin, 2006; Waldron, 2009). However, DISH has not been found in avians. Newcastle disease is a common ailment of captive 
ratites resulting in the inability for the individual to lift their head (Stewart, 1994; Huchzermyer, 2002). However, this is a neurological disease and does not affect the bone. Alternative conditions that affect vertebrae in avians include arthritis, osteopetrosis (viral infection in avians) and vertebral osteomyelitis (bacterial or fungal) (Julian, 1998; Stalker et al., 2010; Doneley, 2011).

Internal inspection provided further evidence for infection of the zygapophysis due to the presence of lesions surrounded by densely compact bone as compared to the normal zygapophysis (Figure 2B-D). Reactive arthritis has been identified in avians, but within long bone joints (MacLean et al., 2013), and the lack of soft tissue makes it difficult to diagnose in this specimen. Osteopetrosis is characterised by the proliferation of porous subperiosteal bone, which is not seen in BHI 6241 (Ritchie, Harrison \& Harrison, 1994). Osteomylitic infection of the vertebral column has been noted in broiler chickens; however, cases affect the centrum and not the processes as seen in this specimen (Julian, 1998; Stalker et al., 2010). In snakes, vertebral osteomyelitis can cause anklyosing (fusion) of the vertebrae similar to what is seen in BHI 6241 (Stacy and Pessier, 2007). Although this is a squamate comparison, the description is the closest to what is seen in BHI 6241. Thus the suggested diagnosis is partial ankylosing due to a form of vertebral osteomyelitis.

BHI 3033: The T. rex cervical vertebrae associated with this rib exhibit severe reactive bone growth, most likely due to a complication of healing after trauma, which caused two of the cervicals to become fused (Larson \& Donnan, 2002; pers. comm. Larson, 2013). The complication derived from the vertebral injury appears to have spread to the cervical rib, giving it a frothy appearance, and in some areas it is enlarged (Figure 3). The most likely cause is osteitis or osteomyelitis as a result of complications during healing.

Internal examination reveals high levels of porosity, with canals lined parallel to the long axis of the rib, which is the normal condition (Figure 3B-C, E). There are no signs of necrosis to suggest an exudative reaction like that seen in bacterial infection (Huchzermyer, 2003); however, there is reactive bone growth present towards the distal end of the section (red arrows). The fusion of the cervical vertebrae associated with this rib suggests a similar condition as seen in BHI 6241, where an infection of the cervicals results in inflammation of the bone/marrow cavity and anklyosing of the vertebrae. Although osteomyelitis does not always result in periosteal new bone growth in birds and reptiles, it can cause anklyosing between affected vertebrae similar to what is seen in the associated cervicals (Mader, 2006). Other conditions that could cause bone inflammation are not applicable as they typically affect the joints (gout, arthritis; Berners; 2002; Mader, 2006) or are rare in ribs (osteopetrosis; Ritchie, Harrison \& Harrison, 1994). However, as osteomyelitis is difficult to diagnose in extant reptile using X-ray techniques (such as radiographs), we can only tentatively diagnosis this as a form of osteomyelitis.

BHI 6191: The E. annectens metacarpal displays a rough fracture callus (poorly remodelled) that surrounds a badly displaced fracture (Figure 4). The pathological tissue is very porous and includes several large lesions continuing past the callus and through the metacarpal (Figure 4BC). The original morphology of the metacarpal can be seen in the transverse view (Figure 4D) including some laminar histological features, though there is severe angular compaction and 
displacement (Figure 4B, D). The metacarpal becomes increasingly hard to discriminate from the internal pathological growth moving distally from the apparent fracture plane, with the bone's ends completely encompassed into the pathological mass (Figure 4B, C). The diagnosis for this pathology is osteomyelitis caused by fracture complications based on the misalignment of the fractured pieces, internal necrosis and islands of 'normal' tissue (Rothschild \& Martin, 2006; Stacy and Pessier, 2007; Gál, 2008; Waldron, 2009).

Other common degenerative conditions known to affect archosaur digits include arthritis, gout, neoplasia, and fibrous osteodystrophy (Mader, 2006). Arthritis and gout, which are the most common of these conditions (within archosaurs), can be excluded as both affect the joints (Mader, 2006). Fibrous osteodystrophy is known to weaken long bones, increasing the occurrence of fractures, as well as cause massive bone turnover (Mader, 2006). However, it is also marked by thinning of bone tissue, which is not seen in BHI 6191. Neoplasia could be an alternative diagnosis, as it is known to cause both reactive bone growth and destroy original bone tissue (Mader, 2006; Doneley, 2011). However, as cancers are fairly rare in wild archosaurs (Effron, Gariner and Benirschke, 1977; Siegfried, 1982; Garner, Hernandez-Divers and Raymond, 2004; Rothschild \& Martin, 2006), we maintain the diagnosis as osteomyelitis caused by complications of a fracture.

BHI 6184: Externally, the exostosis expands radially from the E. annectens rib with no distinguishable boundary between the pathological and normal tissues (Figure 5). The 'pursed' external morphology is seen internally as a secondary protrusion in medial-lateral view (Figure $5 \mathrm{C}$ ) and as a simple outgrowth of reactive bone in dorsal-ventral and transverse views (Figure $5 \mathrm{~B}, \mathrm{D})$. The original hypothesis suggested that the growth of bone occurred around an embedded foreign object such as a tooth, which has been seen in other hadrosaurians (DePalma et al., 2013). However, there is no indication here of an embedded fragment.

Another possibility is periostitis, which results in irregular periosteal reactive bone growth (Waldron, 2009). Periostitis can be remodelled, giving a smooth outside texture with time; however, in this example there is no definition between the pathological growth and normal bone surface as expected in periostitis (Figure 5B-D). Soft bone diseases such as rickets/osteomalacia can also cause such deformities. Osteomalacia is the softening of the bones seen in young crocodilians as a result of an inability to ossify osteoid, and is usually caused by poor calcium intake (Huchzermyer, 2003; Waldron, 2009). However, the lack of preservation of osteoid in fossilised tissues makes it difficult to assess osteomalacia in the fossil record (Rothschild \& Martin, 2006). Finally, the protrusion could be a fracture callus as reptile rib fractures usually show no fracture line, but rather an increase in rib diameter (Mader, 2006). However, the other characteristics of reptilian rib fracture, such as a thinning of the cortex and widening of the medullary cavity is not observed (Mader, 2006). Therefore, we cannot diagnose the pathological condition beyond an abnormal growth of folded ossified tissue.

\section{Conclusions}

Although palaeopathological interpretation is restricted, to a degree, due to loss of information during fossilisation, detailed internal microstructural information can drastically improve the characterisation of pathological tissues. High-resolution CT (specifically XMT) provides a nondestructive means to view and aid in the diagnosis of complex internal morphologies of 
242 paleopathologies. In this study, XMT revealed fine detail morphological features that were 243 necessary for a more informative diagnosis, including the correction of misinterpretations

244 (ostrich, Edmontosaurus rib). Thus, for future studies, we suggest the application of both internal 245 and external morphological descriptions when diagnosing palaeopathologies through the use of 246 X-ray microtomography, especially when the application of thin section analysis is either not 247 available or possible (due to rarity of sample).

Acknowledgements

250 We would like to thank the Black Hills Institute and the Natural History Museum (Tring) for the 251 loan of specimens and the Manchester X-ray Imaging Facility. 


\section{References}

1. Berners, J.D. 2002. Foot conditions. Ch. 8 in Cooper, J.E. (ed.) Birds of prey: health and disease, 3rd Ed. Oxford, UK: Blackwell Science Ltd.: pp 122-131.

2. Bishop P.J., Walmsley C.W., Phillips M.J., Quayle M.R., Boisvert C.A., McHenery, C.R. 2015. Oldest pathology in a tetrapod bone illuminates the origin of terrestrial vertebrates. PLoS ONE 10(5): e0125723. doi: 10.1371/journal.pone.0125723

3. DePalma II, R.A., Burnham, D.A., Martin, L.D., Rothschild, B.M., Larson, P.L. 2013. Physical evidence of predatory behaviour in Tyrannosaurus rex. Proceedings of the Natural Academy of Science 110(31): 12560-12564. doi:10.1073/pnas.1216534110.

4. Doneley, B. 2011. Avian Medicine and Surgery in Practice: Companion and Aviary Birds. Boca Raton, FL. Taylor \& Francis Group, LLC.

5. Effron, M., Griner, L. and Benirschke, K. 1977. Nature and rate of neoplasia in captive wild mammals, birds and reptiles at necropsy. Journal of the National Cancer Institute 59(1): 185-198.

6. Englke, K., Karolczak, M., Lutz, A., Shelbert, U., Schaller, S., Kalender W. 1999. MikroCT: Technologie un application zur erfassung von knochenartchitektur. Radiologe 39: 203-212.

7. Foth C., Evers, S.W., Pabst, B., Mateus, O., Flisch, A., Patthey, M., Rauhut O.W.M. 2015. New insights into the lifestyle of Allosaurus (Dinosauria: Theropoda) based on another specimen with multiple pathologies. PeerJ3:e940 .

8. Gál, E. 2008. Bone evidence of pathological lesions in domestic hen (Gallus domesticus Linnaeus, 1758). Veterinarija Ir Zootechnika 41 (63): 42-48.

9. Garner, M.M., Hernandez-Divers, S.M., Raymond, J.T. 2004. Reptile neoplasia: a retrospective study of case submissions to a speciality diagnostic services. Veterinary Clinics of North America: Exotic Animal Practice 7: 653-671.

10. Gentz, E.J. 1996. Fusobacterium necrophorum associated with bumblefoot in a wild great horned owl. Journal of Avian Medicine and Surgery 10(4): 258-261.

11. Harmon, B.G. 1998. Avian heterophils in inflammation and disease resistance. Poultry Science 77: 972-977.

12. Herman, C.M., Locke, L.N., Clark, G.M. 1962. Foot abnormalities of wild birds. BirdBending 33(4): 191-198.

13. Huchzermyer, F.W. 2002 Diseases of farmed crocodiles and ostriches. Scientific and Technical Review of Office International des Epizooties 21(2): 265-276.

14. Huchzermyer, F.W., Cooper, J.E. 2000. Fibriscess, no abscess, resulting from localised inflammatory response to infection in reptiles and birds. Veterinary Record 147: 515-517.

15. Julian, R.J. 1998. Rapid growth problems: Ascites and skeletal deformities in broilers. Poultry Science 77: 1773-1780.

16. Keymer, I.F. 1972. Diseases of birds of prey. Veterinary Record 90: 579-594.

17. Kranenburg, H.C., Hazewinkel, H.A.W., Meij, B.P. 2013. Spinal hyperostosis in humans and companion animals. Veterinary Quarterly 33 (1): 30-42.

18. Larson, P.L., Donnan, K. 2002. Rex Appeal. Montpelier: Invisible Cities Press.

19. Limaye, A. 2006. Drishti - Volume Exploration and Presentation Tool, Poster presentation, Vis, Baltimore.

20. Mader, D.R. 2006. Reptile Medicine and Surgery. St. Louis, MO: Saunders Elsevier.

21. Morishita, T.Y., Aye, P.P., Brooks, D.L. 1997. A survey of diseases of raptorial birds. Journal of Avian Medicine and Surgery 11(2): 77-92. 
22. McLean, R., Beaufrère, H., Heggem-Perry, B., Field, C., Garner, M. 2013. 2013. Presumed reactive polyarthritis and granulomatous vasculitis in a Mississippi sandhill crane (Grus canadensis pulla). Journal of Avian Medicine and Surgery 27(4): 309-314.

23. Particelli, F., Mecozzi, L., Beraudi, A., Montesi, M., Baruffaldi, F., Viceconti, M. 2012. A comparison between micro-CT and histology for the evaluation of cortical bone: effect of polymethylmethacrylate embedding on structural parameters. Journal of Microscopy 245(3): 302-310.

24. Ritchie, B.W, Harrison, G.J. and Harrison, L.R. 1994. Avian Medicine: Principals and Application. Lake Worth, FL: Wingers publishing, Inc.

25. Remple, J.D., Al-AShbal, A.A. 1993. Raptor bumblefoot: Another look at histopathology and pathogens. Ch. 17 in Redig, P., Cooper, J., Remple, J.D., Hunter, B. (eds.) Raptor Biomedicine. Minneapolis, MN: University of Minnesota Press: pp 92-153

26. Rothschild, B., Depalma, R. 2013. Skin pathology in the Cretaceous: Evidence for probable failed predation in a dinosaur. Cretaceous Research 42: 44-47

27. Rothschild, B., Martin, L. 2006. Skeletal impact of disease. Bulletin: New Mexico Museum of Natural History \& Science 33.

28. Rothschild, B.M., Panza, R.K. 2005. Epidemiologic assessment of trauma-independent skeletal pathology in non-passerine birds from museum collections. Avian Pathology 34 (3): 212-19. doi:10.1080/03079450500096455.

29. Rühli, F.J., Kuhn, G., Evison, R., Müller R., Schultz M. 2007. Diagnostic value of microCT in comparison with histology in the qualitative assessment of historical human skull bone pathologies. American Journal of Physical Anthropology 133(4): 1099-1111.

30. Schindelin J., Arganda-Carreras, I., Frise, E., Kaynig, V., Longair, M., Pietzsch, T., Preibisch, S., Rueden, C., Saalfeld, S., Schmid, B., Tinevez, J.-Y., White, D.J., Hartenstein, V., Eliceiri, K., Tomancak, P., Cardona, A. 2012. Fiji: an open-source platform for biological-imaging analysis. Nature Methods 9(7): 676-682.

31. Siegfried, L.M. 1982. Neoplasms identified in free-flying birds. Avian Diseases 27(1): 86-99.

32. Stewart, J. 1994, Ch. 48 in Ritchie, B.W, Harrison, G.J. and Harrison, L.R. (eds.). Avian Medicine: Principals and Application. Lake Worth, FL: Wingers publishing, Inc.: pp. 1284-1326.

33. Stacy, B. A., Pessier, A.P. 2007. Host response to infectious agents and identification of pathogens in tissue section. Ch5 in E. Jacobson (ed.) Infectious Diseases and Pathology of Reptiles: Color atlas and text: pp 257-298.

34. Stalker, M.J., Brash, M.L., Weisz, A., Ouckama, R.M., Slavic, D. 2010. Arthritis and osteomyelitis associated with Enterococcus cecorum infection in broiler and broiler breeder chickens in Ontario, Canada. Journal of Veterinary Diagnostic Investigation 22: 643-645.

35. Straight, W., Davis, G., Skinner, C., Haims, A., McClennan, B., Tanke, D. 2009. Bone lesions in Hadrosaurus: Computed tomographic imaging as a guide for paleohistolological and stable-isotope analysis. Journal of Vertebrate Paleontology 29(2): 315-325.

36. Sutton, M., Rahman, I., Garwood, R. 2014. Techniques for Virtual Palaeontology. Chichester PO19 8SQ, UK: John Wiley \& Sons, Ltd.,

37. Thali, M. J., Taubenreuther, U., Karolczak, M., Braun, M., Brueschweiler, W., Kalender, W. A., Dirnhofer, R. 2003. Forensic microradiology: Micro-Computed Tomography 
(Micro-CT) and analysis of patterned injuries inside of bone. Journal of Forensic Science 48(6): 1336-1342.

38. Waldron, T. 2009. Paleopathology. New York, New York: Cambridge University Press.

39. Wyss, F., Schumacher, V., Wenker, C., Hoby, S., Gobeli, S., Arnaud, A., Engels, M., Friess, M., Lange, C.E., Stoffek, M.H., Robert, N. 2015. Pododermatitis in captive and free-ranging greater flamingos (Phoenicopterus Roseus). Veterinary Pathology, January. doi: $10.1177 / 0300985814568359$. 
Table $\mathbf{1}$ (on next page)

External descriptions of specimens

External pathological description for extant and extinct archosaurs used in this study. 


\begin{tabular}{|l|l|l|}
\hline \multicolumn{1}{|c|}{ Species } & Skeletal Element & \multicolumn{1}{c|}{ External Pathological Description } \\
\hline $\begin{array}{l}\text { Sagittarius } \\
\text { serpentarius } \\
\text { (secretary bird) }\end{array}$ & $\begin{array}{l}\text { pedal phalanx } \\
\text { NHM } \\
\text { S/1869.2.16.1 }\end{array}$ & $\begin{array}{l}\text { Extreme bone growth; most of the digit is } \\
\text { obscured }\end{array}$ \\
\hline $\begin{array}{l}\text { Struthio camelus } \\
\text { (ostrich) }\end{array}$ & $\begin{array}{l}\text { cervical vertebra } \\
\text { BHI 6241 }\end{array}$ & $\begin{array}{l}\text { Bony growth on the postzygapothoses } \\
\text { resulting in pseudofusion of two vertebrae }\end{array}$ \\
\hline \multicolumn{2}{|l|}{} \\
\hline $\begin{array}{l}\text { Tyrannosaurus rex } \\
\text { Edmontosaurus } \\
\text { annectens }\end{array}$ & $\begin{array}{l}\text { cervical rib } \\
\text { BHI 3033 }\end{array}$ & Extensive reactive bone throughout \\
\hline $\begin{array}{l}\text { Edmontosaurus } \\
\text { annectens }\end{array}$ & $\begin{array}{l}\text { BHI 6191 } \\
\text { dorsal rib }\end{array}$ & $\begin{array}{l}\text { Rough fracture callus caused by angular } \\
\text { displacement }\end{array}$ \\
\hline
\end{tabular}

1 
Table 2 (on next page)

Table of scanning parameters

Experimental parameters used for scanning with the Nikon Metris Custom Bay (MXIF). 


\begin{tabular}{|l|r|r|r|r|r|r|}
\hline \multicolumn{1}{|c|}{ Species } & \multicolumn{1}{|c|}{$\mathrm{kV}$} & \multicolumn{1}{|c|}{$\begin{array}{c}\text { Filter } \\
(\mathrm{mm})\end{array}$} & $\begin{array}{c}\text { Exposure } \\
(\mathrm{ms})\end{array}$ & $\begin{array}{c}\text { Voxel size } \\
(\mu \mathrm{m})\end{array}$ & $\begin{array}{c}\text { Total Scan } \\
\text { Time } \\
(\mathrm{min})\end{array}$ \\
\hline Sagittarius serpentarius & 50 & 150 & $\mathrm{none}$ & 1000 & 16.6 & 55 \\
\hline Struthio camelus & 60 & 170 & $1.5 \mathrm{Al}$ & 1000 & 44.9 & 55 \\
\hline Tyrannosaurus rex & 60 & 170 & $1.5 \mathrm{Al}$ & 1000 & 15.3 & 55 \\
\hline $\begin{array}{l}\text { Edmontosaurus } \\
\text { annectens - metacarpal }\end{array}$ & 115 & 115 & $0.25 \mathrm{Cu}$ & 500 & 47.9 & 30 \\
\hline $\begin{array}{l}\text { Edmontosaurus } \\
\text { annectens - rib }\end{array}$ & 115 & 85 & $0.25 \mathrm{Cu}$ & 708 & 78 & 40 \\
\hline
\end{tabular}




\section{1}

S. serpentarius (NHM S/1869.2.16.1) pedal phalanx

S. serpentarius (NHM S/1869.2.16.1) pedal phalanx; photograph of the specimen in plantar view (A), XMT slices in medial-lateral (B), dorsal-ventral (C) and transverse (D) views, and 3D rendering of the plantar (E) and distal (F) surfaces. A large, circular lesion is seen on the plantar surface (red arrows; A, E), with small necrotic spaces persisting throughout the phalanx (red arrows B, C). Extensive reactive bone growth persists both internally and externally. The outline of the normal bone cortex is barely visible in some areas and indistinguishable in others (red circles; D, F). The extent of the growth makes it difficult to identify any possible indicators of trauma. Both articulation surfaces are relatively untouched. Scale bar is $1 \mathrm{~cm}$. 
A
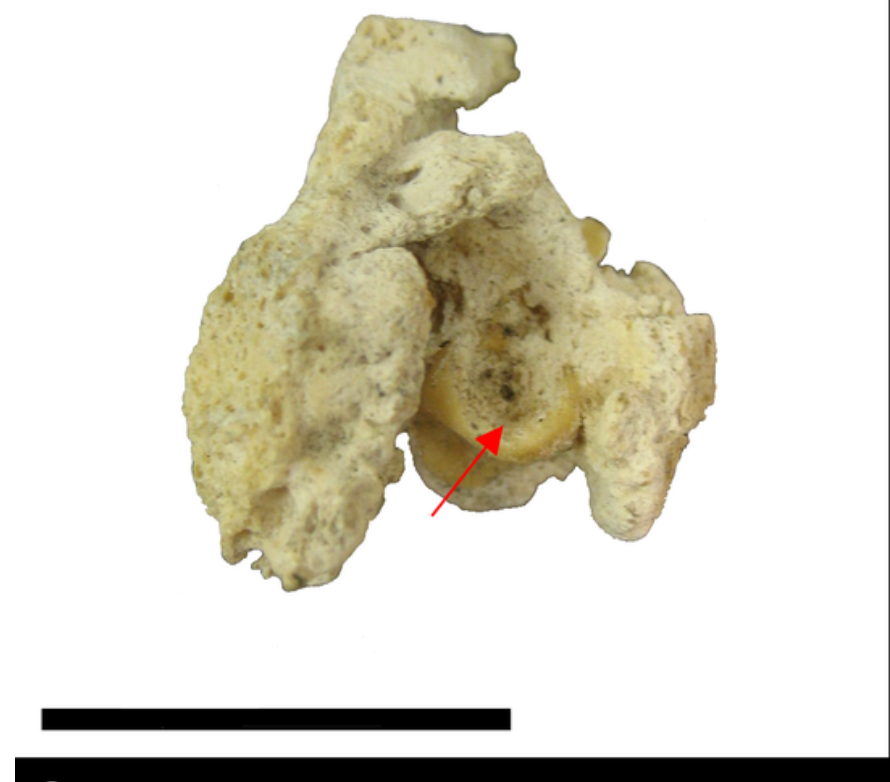

C
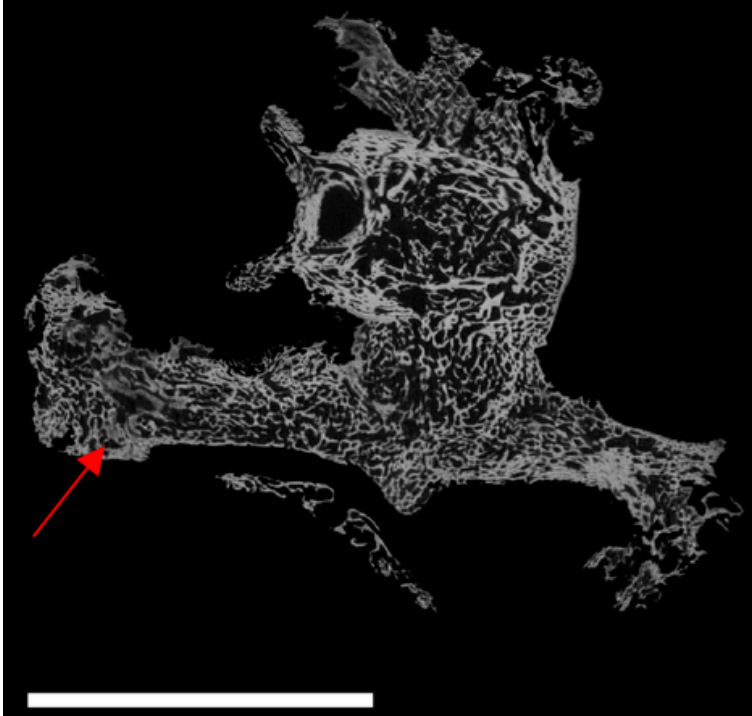

E

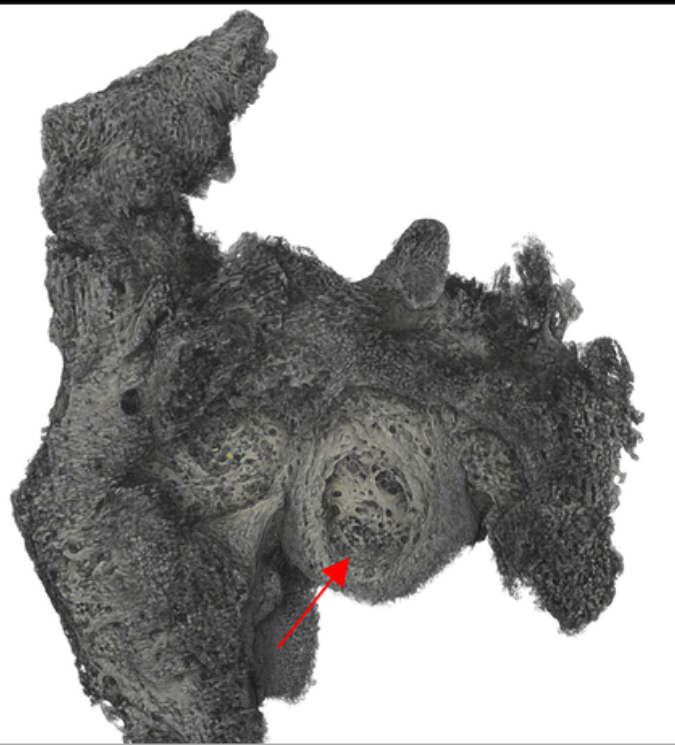

Peer] reviewing $\mathrm{RD}$
B

D

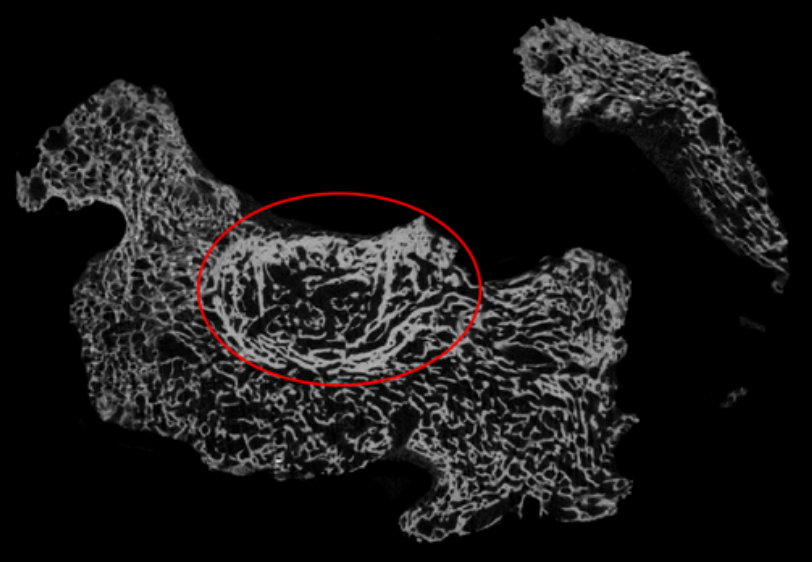

F

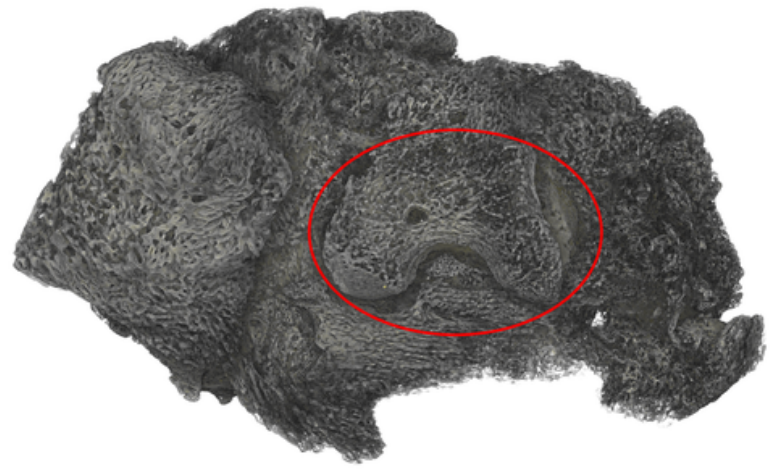


2

S. camelus (BHI 6241) cervical vertebra

S. camelus (BHI 6241) cervical vertebra; photograph of the specimen in medial-lateral view (A) and XMT slices in medial-lateral (B), dorsal-ventral (C) and transverse (D) views. The affected zygapophysis shows large necrotic cavities (red arrows) surrounded by relatively dense reactive bone, which spreads both internally and externally to form osteophyte 'hooks'. Scale bar is $1 \mathrm{~cm}$. 


\section{A}

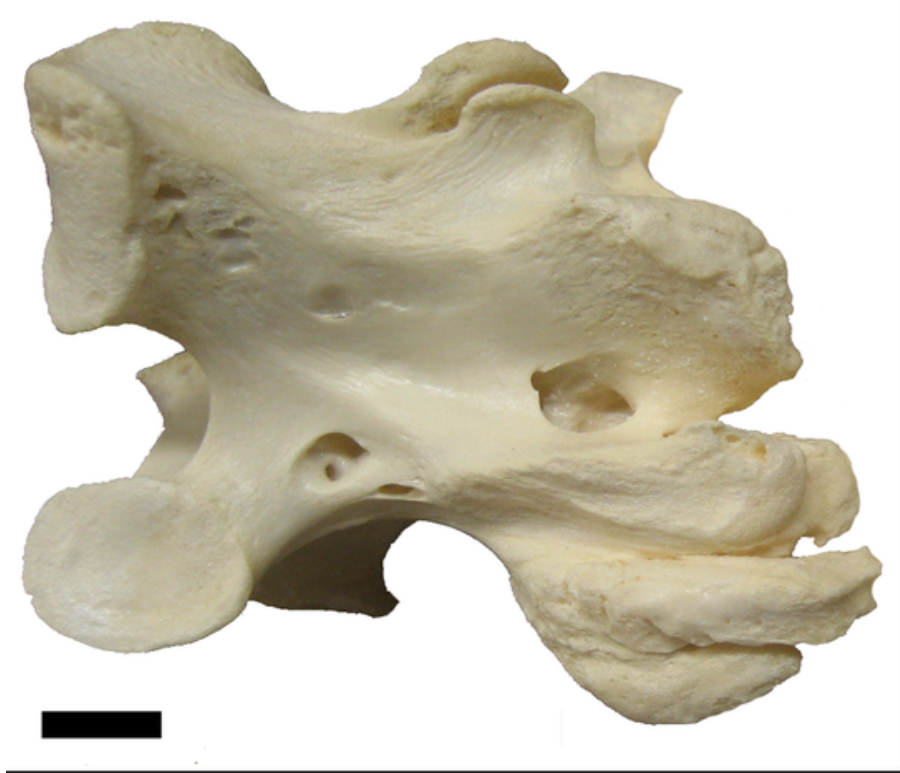

C

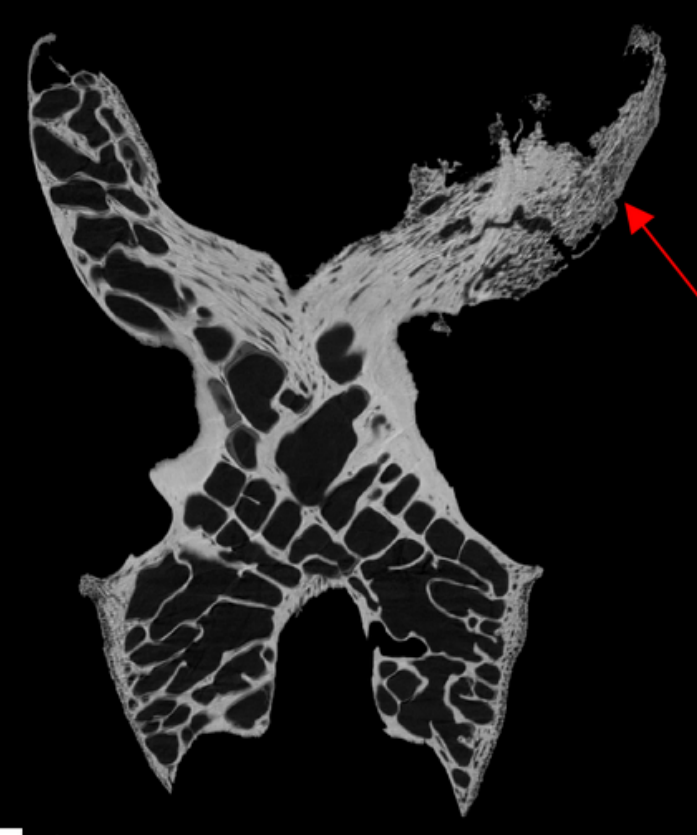

B

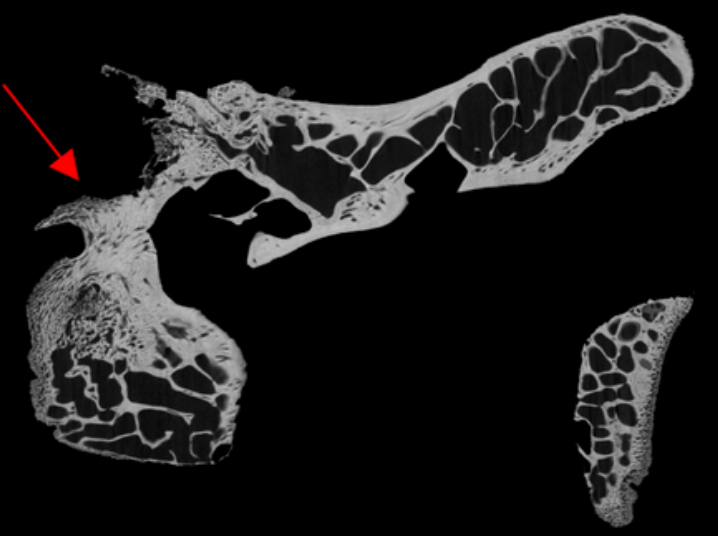

D

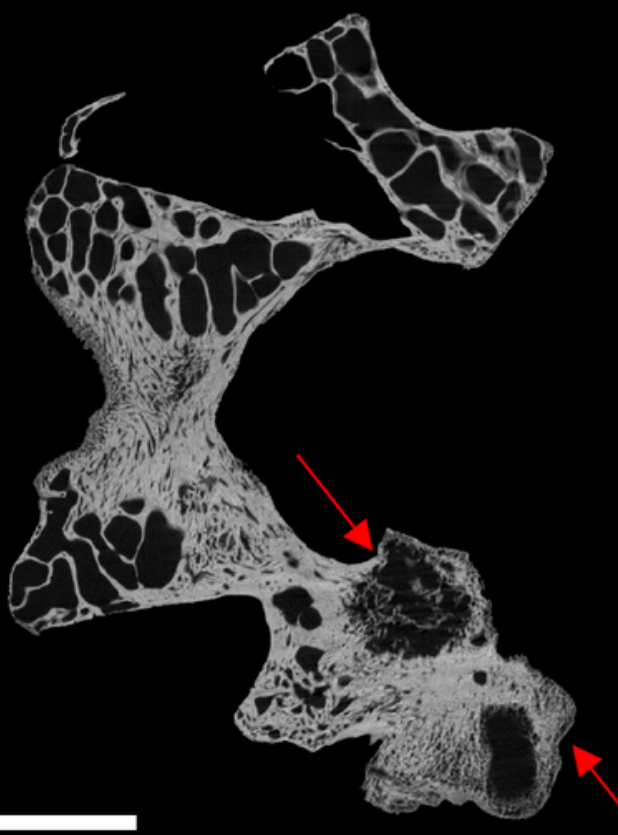


3

T. rex (BHI 3033) cervical rib

T. rex (BHI 3033) cervical rib; photograph of the specimen in rostral-caudal view (A), XMT slices in medial-lateral (B), rostral-caudal (C) and transverse (D) views, and 3D rendering in medial-lateral view (E). Reactive bone is observed in some concentrated areas (red arrows). The high porosity consists of long canals running parallel to the long axis of the specimen ( $E$ in yellow). Scale bar is $5 \mathrm{~mm}$. 
PeerJ Reviewing Manuscript

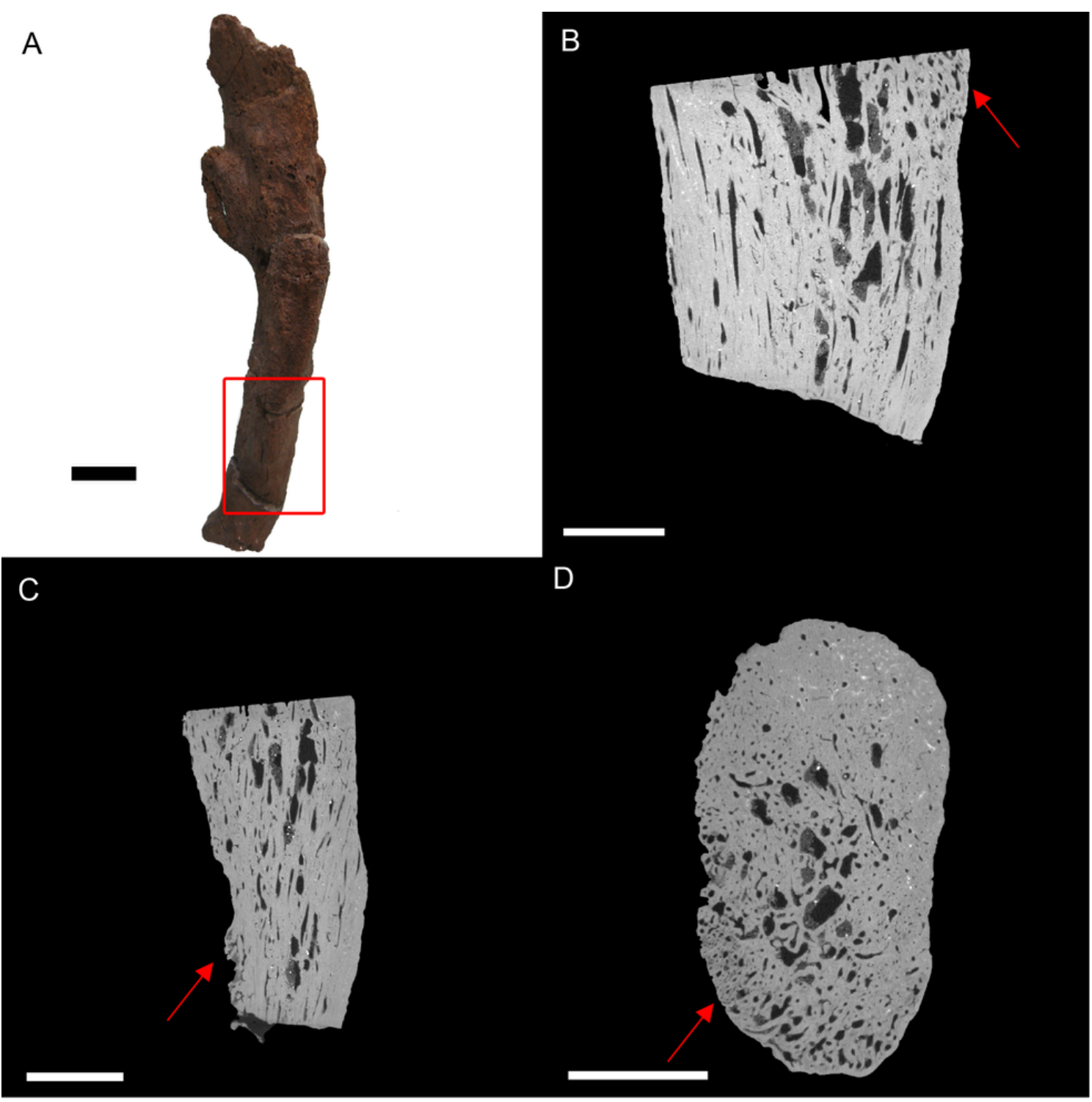

E

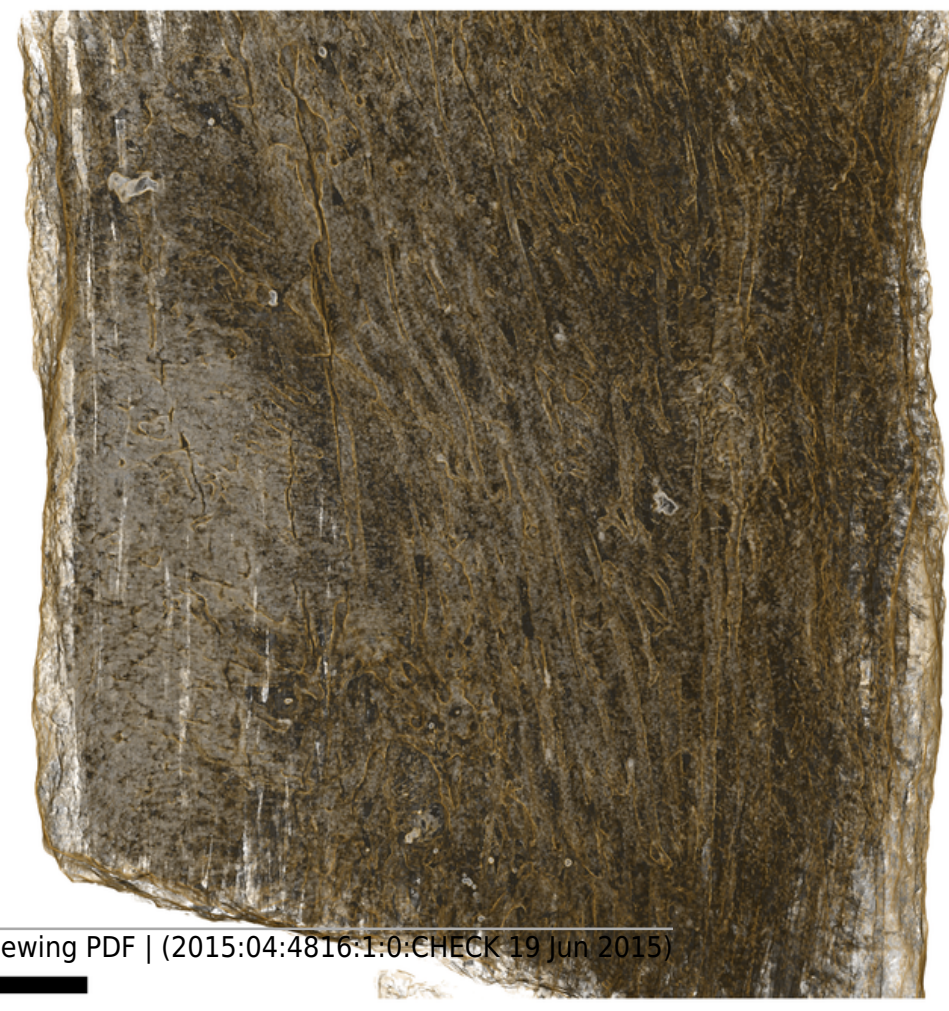

Peer reviewing PDF | (2015:04:4816:1:0:CHECK 19 Jun 2015) 


\section{4}

E. annectens (BHI 6191) metacarpal

E. annectens (BHI 6191) metacarpal; photograph of the specimen in medial-lateral view (A) and XMT slices in medial-lateral (B), dorsal-ventral (C) and transverse (D) views. A fracture probably caused by crushing is seen in the centre of the element, with severe angular misalignment (B). Reactive bone persists throughout the entire metacarpal, with a large rough fracture callus (poorly remodelled). Several necrotic areas are seen throughout the specimen (red arrows B, C). The ends of the metacarpal are almost completely resorbed and replaced with reactive bone (C). Despite the extent of resorption and reactive bone growth, some of the original laminar features can still be seen (red circle D). Scale bar is $1 \mathrm{~cm}$. 
A

C

c
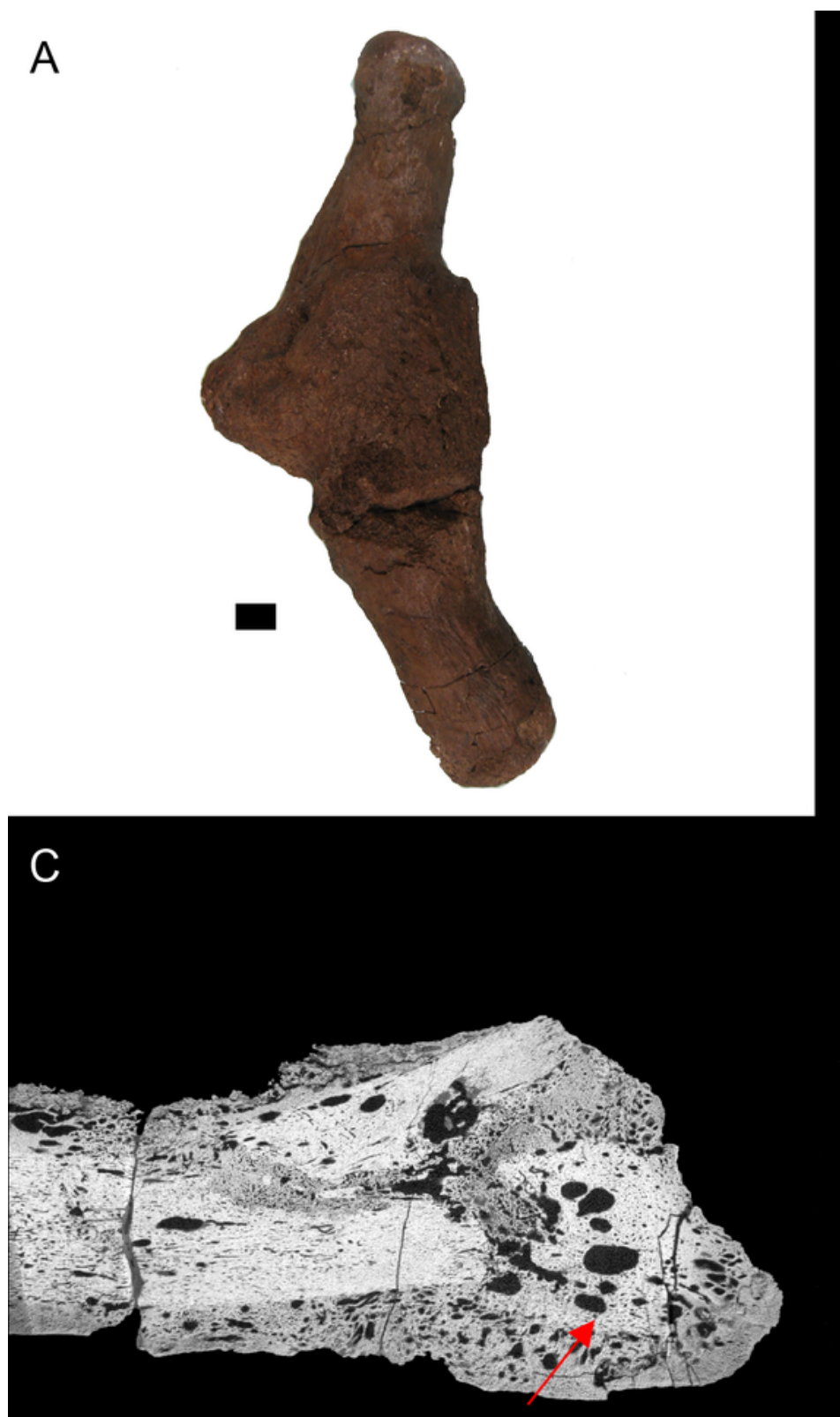

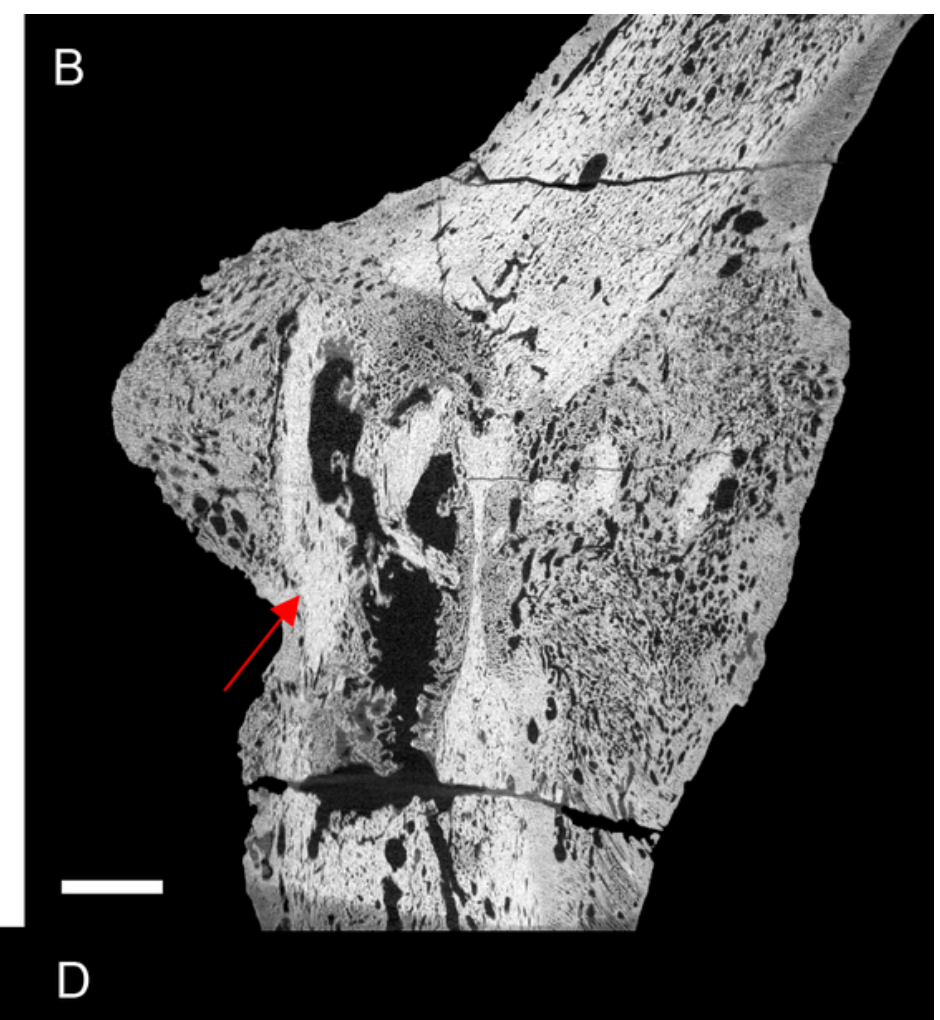




\section{5}

E. annectens (BHI 6184) dorsal rib

E. annectens (BHI 6184) dorsal rib; photograph of the specimen in rostral-caudal view with magnified image of the 'folded tissue' (A) and XMT slices in rostral-caudal (B), medial-lateral (C) and transverse (D) views. The reactive bone growth is localised to one side of the rib (red boxes $B, D)$. There are no signs of trauma, though smaller fractures may be concealed within the pathological mass. The "folded" morphology of the pathological mass is seen as an outgrowth of bone (red arrow C). Scale bar is $1 \mathrm{~cm}$. 


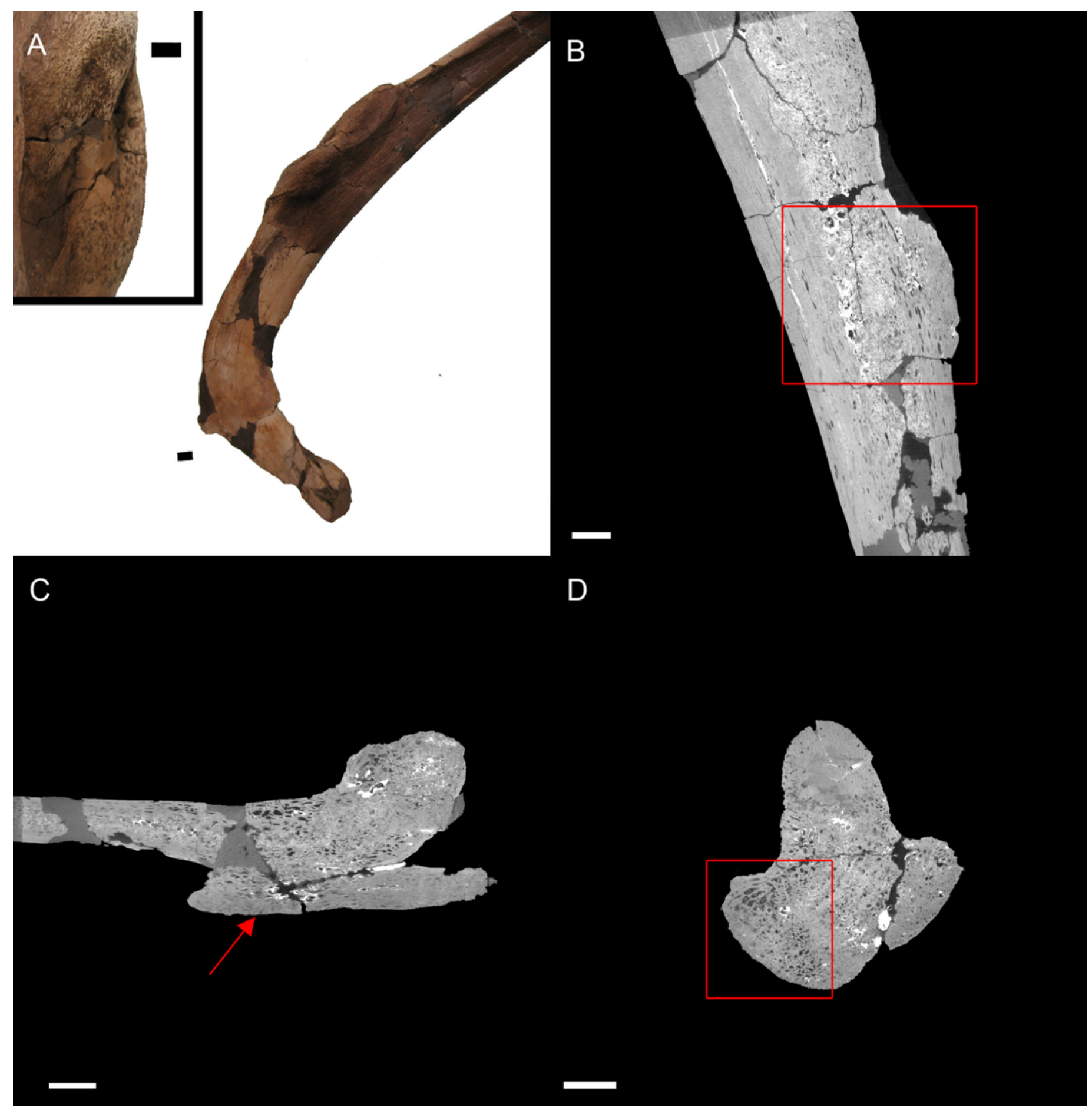

